\title{
Cu-Mo Thin Film Electrodeposited at a Rate of Megahertz by a Rectangular Pulse Current Technique
}

\author{
M. Saitou \\ University of the Ryukyus, Department of Mechanical Systems Engineering, 1 Senbaru Nishihara-cho \\ Okinawa, 903-0213, Japan. \\ E-mail: saitou@tec.u-ryukyu.ac.jp
}

doi: $10.20964 / 2017.02 .26$

Received: 17 November 2016 / Accepted: 9 December 2016 / Published: 30 December 2016

$\mathrm{Cu}-\mathrm{Mo}$ thin films generated on ITO glasses by a rectangular pulse current technique having a frequency of megahertz were investigated using energy dispersive X-ray spectroscopy (EDX), X-ray diffraction (XRD), and scanning electron microscope (SEM). The concentration of Mo in the $\mathrm{Cu}-\mathrm{Mo}$ thin film measured with EDX, which periodically changed with the frequency of the rectangular pulse current, had a maximum concentration of $9 \mathrm{wt} \%$. XRD analysis revealed diffraction peaks of the $\mathrm{Cu}-$ Mo thin film consistent with those of the crystallographic planes such as (111), (200), (220), (311), and (222) planes of polycrystalline copper. SEM images of the $\mathrm{Cu}$-Mo thin film showed an aggregation of an island of which the surface appeared like a cauliflower in nano scale size. These experimental results indicate that the $\mathrm{Cu}-\mathrm{Mo}$ thin film generated in an aqueous solution that does not include the iron-group element is an alloy composed of $\mathrm{Cu}$ and Mo. The oscillatory behavior of the Mo concentration in the $\mathrm{Cu}$-Mo thin film is explained by an energy level transition of electron that causes a resonant generation of $\mathrm{Cu}$ and $\mathrm{Mo}$.

Keywords: Cu-Mo thin film; Aqueous solution; Energy level transition; Nano cauliflower; Resonant generation; Alloy

\section{$\underline{\text { FULL TEXT }}$}

(C) 2017 The Authors. Published by ESG (www.electrochemsci.org). This article is an open access article distributed under the terms and conditions of the Creative Commons Attribution license (http://creativecommons.org/licenses/by/4.0/). 